- Technical Report

\title{
Fundamental Study of Gas Toxicity with Respect to Fire Stages
}

\author{
Xuansu Zhao ${ }^{1}$, Hideki Yoshioka ${ }^{2}$, Takafumi Noguchi ${ }^{1}$, Satoshi Fujimoto ${ }^{3}$, Yutaka Tanaike ${ }^{1}$, \\ Tetsuya Hayakawa ${ }^{4}$, Yoshihiro Hase ${ }^{5}$ and Tomohiro Naruse ${ }^{6}$ \\ ${ }^{1}$ The University of Tokyo, Japan \\ ${ }^{2}$ National Institute for Land and Infrastructure Management, Japan \\ ${ }^{3}$ Utsunomiya University, Japan \\ ${ }^{4}$ Tokyo System Vac.(TSV), Japan \\ ${ }^{5}$ Mitsubishi Plastics Inc., Japan \\ ${ }^{6}$ Building Research Institute, Japan
}

\begin{abstract}
Current Building Standard Law of Japan estimates fire toxicity of building material in case of fire by gas toxicity test using mice. Because it is an animal test, some problems are identified such as the impossibility of quantitative analysis, and from ethical viewpoints. Gas analysis method is needed as an alternative. In this research, authors report FTIR (Fourier Transform Infrared Spectroscopy) analysis of gases generated from building materials using gas toxicity test equipment and a tube furnace. The possibility of replacing animal test with FTIR gas analysis test was discussed.
\end{abstract}

Keywords: Fire Toxicity, Component Analysis, Fire Hazard, The Tube Furnace, The Gas Toxicity Test

\section{INTRODUCTION}

The Building Standards Act was revised in 2000 with the addition of a new gas toxicity test to the existing non-combustibility test and heat buildup test in the performance evaluation tests involved in approval by the Ministry of Land, Infrastructure, Transport and Tourism, which evaluates non-combustible materials.

The gas toxicity test evaluates the hazardousness of a combustion gas according to the time until behavioral arrest in mice subjected to the gas produced by applying heat to the test body (22cm square). The drawback is the difficulty in individually evaluating the hazardousness and toxicity of produced gases due to factors such as test results being significantly affected by individual differences between test animals, an inability to conduct a quantitative analysis of gases produced by the decomposition or combustion of specific building materials, and an inability to evaluate differences in gases produced by different combustion conditions during a fire.

In this research, we report the results of an infrared absorbance spectrum wave number composition analysis of combustion products (smoke and gases) generated 
from building materials using gas toxicity test equipment and a tube furnace, and consider the possibility of replacing testing on animals with a gas toxicity test based on component analysis.

\section{GAS TOXICITY TEST EQUIPMENT + FTIR}

\subsection{Outline of Test}

Existing gas toxicity tests use animals and, in order to evaluate the hazardousness and toxicity of combustion product gases from building materials, test results must be quantified and their validity ascertained. In our test, we used gas toxicity test equipment to burn construction materials and then carried out gas component analysis by FTIR. There are some other ingredients of $\mathrm{C}_{3} \mathrm{H}_{4} \mathrm{O}$ such as propadien-1-ol and methylketene, but it is difficult to measure, and the concentration of $\mathrm{C}_{3} \mathrm{H}_{4} \mathrm{O}$ is thought as acrolein to evaluate. Based on those results, we found the hazardousness and toxicity of test bodies and compared them with those found using existing gas toxicity tests.

\subsection{Test Bodies}

We used 11 types of test body, each cut into $22 \mathrm{~cm}$ squares to fit the existing gas toxicity test equipment: (1) wallpaper (polyester, rayon, vinyl chloride, silk), (2) composite panel core material (polyethylene resin with aluminum hydroxide) (3) insulation materials (urethane foam, polyisocyanurate foam, phenolic foam), (4) wood (Japanese cedar: flame retardant treated, semi-flame retardant treated, untreated).

\subsection{Test Method}

We conducted heating tests using the test equipment illustrated in Figure 1. We sampled the combustion product gas from the exhaust outlet a at $4 \mathrm{~L} / \mathrm{min}$ (intermediate emission of $6 \mathrm{~L} / \mathrm{min}$ ) and measured the gas concentration by Fourier transform infrared spectroscopy (referred to below as FTIR). We also measured the exhaust (smoke) temperature at point $\mathrm{b}$ and the internal temperature of the test box at point $c$. Each test body was heated for a total of six minutes, first with a gas burner for three minutes and then with a $1.5 \mathrm{~kW}$ electric heater for another three minutes. Measurements were taken at 30-minute intervals after the start of the test heating. 


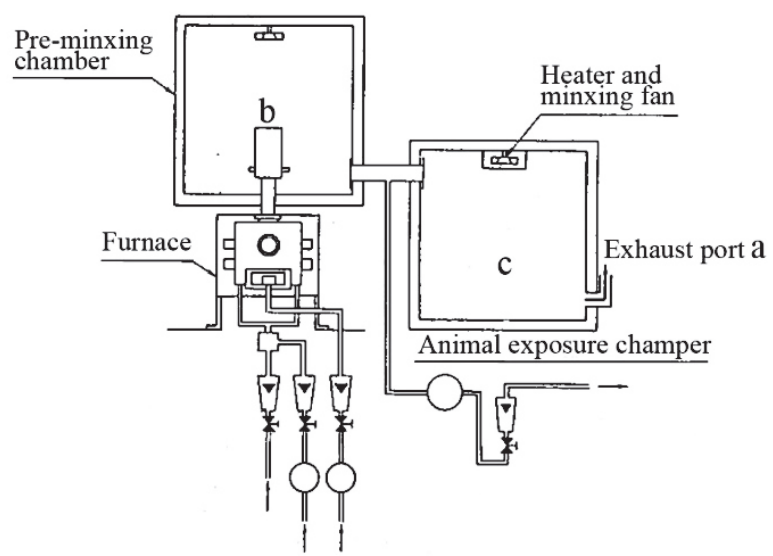

Figure 1 The apparatus of the Fire Smoke Toxicity Test

\subsection{Test Results}

Figure 2-1 shows the main gas and Figure 2-2 shows the CO gas concentration measurement results from the 11 types of test body. The four kinds of wallpaper represented in graphs (a) to (d) all produced acrolein $\mathrm{C}_{3} \mathrm{H}_{4} \mathrm{O}$ and there were relatively high concentrations of $\mathrm{NO}$ from rayon and $\mathrm{HCN}$ from silk. Polyethylene resin, represented in graph (e), includes aluminum hydroxide and so its combustion was uniform and gas production constant. Among the three types of insulation material shown in graphs (f) to (h), urethane foam burned more intensely than polyisocyanurate foam and produced a greater amount of hazardous gas, principally HCN. With phenolic foam, there was a high concentration of $\mathrm{SO}_{2}$. Of the three types of wood, represented in graphs (i) to (k), the flame retardant treated and semi-treated materials produced relatively high concentrations of $\mathrm{NH}_{3}$ and the untreated wood produced a lot of HCN.

\subsection{Considerations}

To evaluate the toxicity of test bodies, we calculated gas analysis results by substitution into the following respective equations as stipulated in international standards ISO 13344[1] and ISO 13571[2]. Table 1 shows the calculation results of lethal toxicity $\mathrm{L}_{\mathrm{FED}}$, effective exposure dose $\mathrm{X}_{\mathrm{FED}}$ and effective concentration $\mathrm{X}_{\mathrm{FEC}}$.

\section{【ISO13344】}

Equation developed by Purser

$$
L_{F E D}=\left(\frac{[C O]}{L C_{50, C O}}+\frac{[H C N]}{L C_{50, H C N}}+\frac{[X]}{L C_{50, X}}+\frac{[Y]}{L C_{50, Y}}\right) \times V_{C O_{2}}+Z_{A}+\frac{21-\left[O_{2}\right]}{21-5.4}
$$

[X] : is the concentration, expressed in microliters per litre, of each acid gas like $\mathrm{CO}_{2}$, $\mathrm{SO}_{2}, \mathrm{NO}, \mathrm{NO}_{2}, \mathrm{HCl}, \mathrm{HBr}, \mathrm{HF}$ 
$[\mathrm{Y}]$ : is the concentration, expressed in microliters per litre, of each organic irritant like acrolein and formaldehyde

$\mathrm{V}_{\mathrm{CO} 2}$ : is a multiplication factor for $\mathrm{CO}_{2}$-driven hyperventilation, $\left(=1+\mathrm{e}^{0.14 \times \mathrm{CO} 2-1 / 2}\right)$

\section{【ISO13571】}

Asphyxiant-gas model

$$
X_{F E D}=\sum_{t_{1}}^{t_{2}} \frac{V_{\mathrm{CO}_{2}} \cdot[\mathrm{CO}]}{35000} \Delta t+\sum_{t_{1}}^{t_{2}} \frac{V_{\mathrm{CO}_{2}} \cdot[\mathrm{HCN}]^{2.36}}{1.2 \times 10^{6}} \Delta t
$$

Irritant-gas model

$$
X_{F E C}=\sum \frac{[i r r .]}{F_{i r r} .}
$$

The thresholds of $\mathrm{L}_{\mathrm{FED}}, \mathrm{X}_{\mathrm{FED}}$ and $\mathrm{X}_{\mathrm{FEC}}$ are set to 1.0 as the approximate values at which averagely sensitive people indoors cannot escape.

For test bodies whose identical $\mathrm{L}_{\mathrm{FED}}$ and $\mathrm{X}_{\mathrm{FED}}$ values from our calculation results are identical, we obtained almost the same evaluation results. With $\mathrm{L}_{\mathrm{FED}}$ and $\mathrm{X}_{\mathrm{FED}}$ values of 1.0 or less, polyethylene resin has a smaller suffocating effect and would not produce behavioral arrest even after exposure of 30 minutes. However, the $\mathrm{X}_{\mathrm{FEC}}$ value is above 1.0, which would slow down the speed of movement of escapees subjected to its irritant effect and could prevent them from reaching safety within the allowable escape time.

\begin{tabular}{|c|c|c|c|c|}
\hline \multirow{2}{*}{ Group } & \multirow{2}{*}{ Specimen } & \multicolumn{2}{|c|}{ ISO13344 } & \multirow{2}{*}{$\frac{\text { ISO13571 }}{\text { FEC }}$} \\
\hline & & LFED & FED & \\
\hline \multirow{4}{*}{ Wall paper } & polyester & 0.57 & 0.83 & 0.47 \\
\hline & rayon & 0.65 & 1.17 & 0.58 \\
\hline & vinyl chloride & 0.55 & 0.84 & 0.84 \\
\hline & silk & 0.65 & 1.27 & 0.58 \\
\hline \multirow{4}{*}{$\begin{array}{c}\text { Core material for } \\
\text { sandwich }\end{array}$} & Polyethylene & 0.59 & 0.70 & 1.07 \\
\hline & Urethane foam & 8.63 & 629.42 & 9.01 \\
\hline & Polyisocyanurate foam & 1.39 & 2.55 & 1.14 \\
\hline & Phenolic foam & 0.56 & 0.53 & 0.58 \\
\hline \multirow{3}{*}{$\begin{array}{c}\text { Wood } \\
\text { (Japanese ceder) }\end{array}$} & Wood with treatment & 0.54 & 1.14 & 0.49 \\
\hline & Wood with semi-treatment & 0.46 & 0.90 & 0.37 \\
\hline & Wood without treatment & 2.05 & 6.82 & 2.27 \\
\hline
\end{tabular}

Table 1 The calculation results

In existing gas toxicity tests, a material is failed if mice reach behavioral arrest faster than 6.8 minutes, the standard time until behavioral arrest in mice when using natural red lauan. In the case of urethane foam, although it passes existing gas toxicity tests, all our FTIR-based evaluation values greatly exceeded the results from untreated wood, as seen in Figure 1, thereby indicating a high risk. 
We proposed to calculate the toxic value from measurements of FTIR and judge the risk that materials give to a refugee at the time of a fire. The animal test is using to check the relation of toxic gases and human bodies.

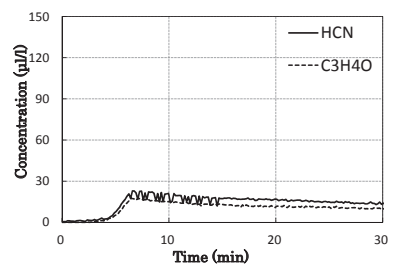

(a) Wall paper: polyester

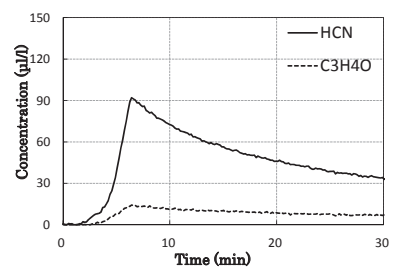

(d) Wall paper: silk

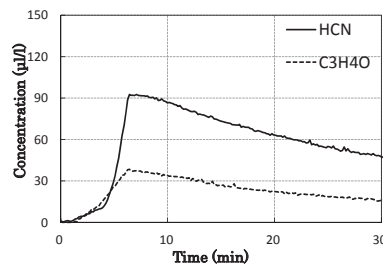

(g) Polyisocyanurate foam

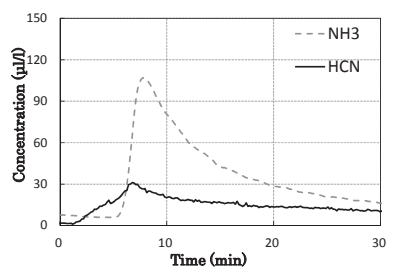

(j) semi-flame retardant treated

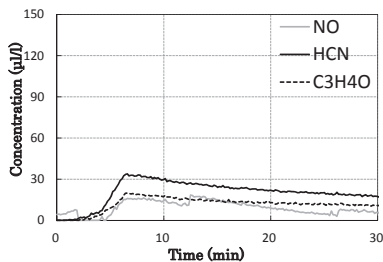

(b) Wall paper: rayon

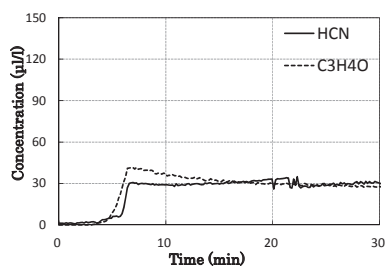

(e) Polyethylene sheet

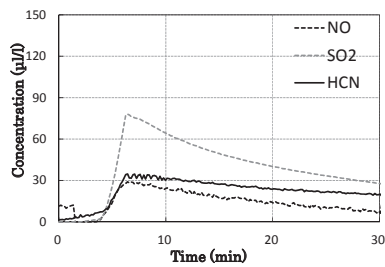

(h) Phenolic foam

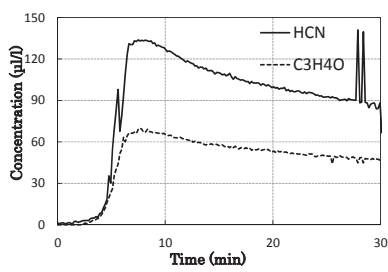

(k) untreated wood

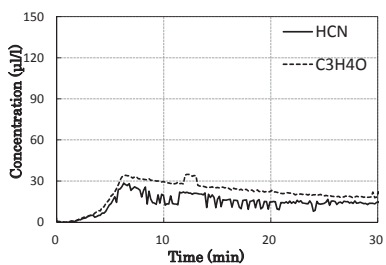

(c) Wall paper: vinyl chloride

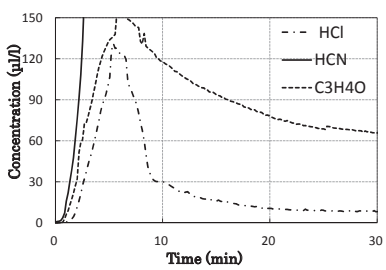

(f) Polyurethane foam

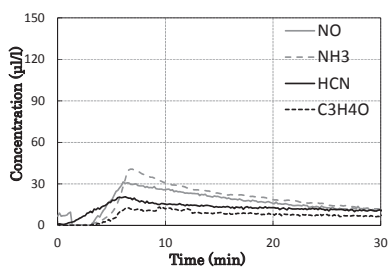

(i) flame retardant treated wood

Figure 2-1 Gas concentration analysis 


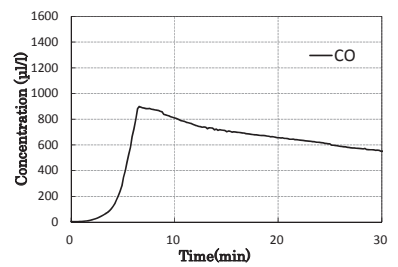

(a) Wall paper: polyester

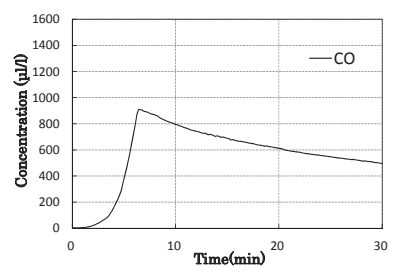

(d) Wall paper: silk

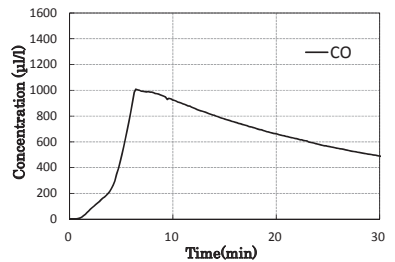

(g) Polyisocyanurate foam

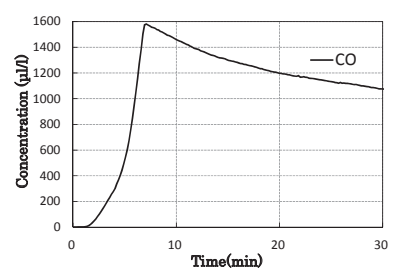

(j) semi-flame retardant treated

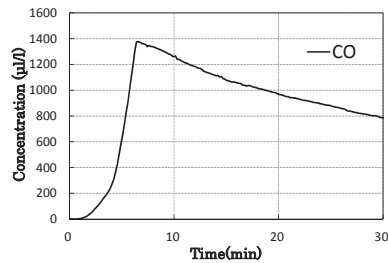

(b) Wall paper: rayon

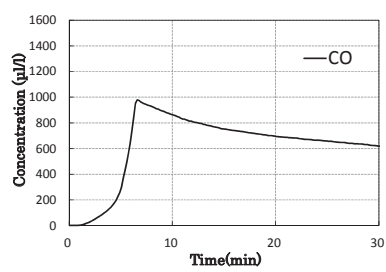

(e) Polyethylene sheet

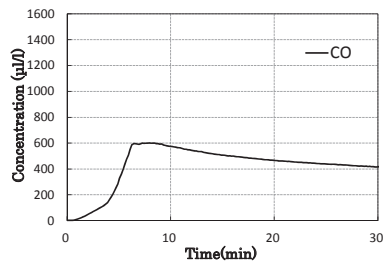

(h) Phenolic foam

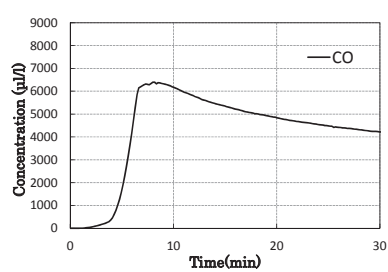

(k) untreated wood

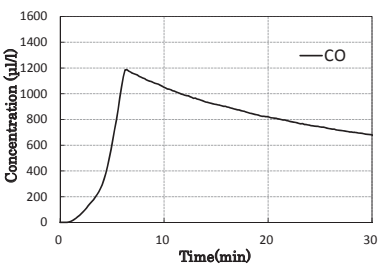

(c) Wall paper: vinyl chloride

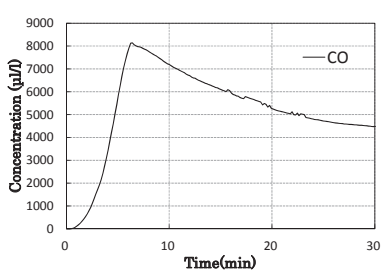

(f) Polyurethane foam

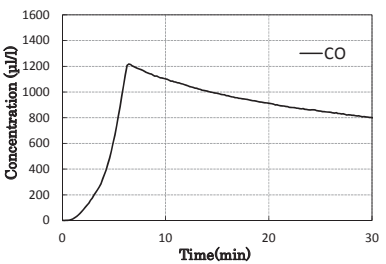

(i) flame retardant treated wood

Figure 2-2 Gas concentration analysis(CO)

\section{TUBE FURNACE + FTIR}

\subsection{Outline of Test}

Understanding the hazardousness and toxicity of combustion product gases from building materials requires clarification of the materials' burning and heat degradation characteristics under various combustion conditions. In our tests, we burned the materials using tube furnace test equipment as stipulated in ISO 19700 and carried out gas component analysis by FTIR. We also looked at the combustion products generated at the progressive stages of a fire in a fire disaster scenario and evaluated their hazardousness and toxicity in order to study the differences in produced gases according to differing combustion conditions during a fire. 


\subsection{Test Bodies}

We used six types of test body, each in pellet or chip form so that they could be evenly set on the test body board: wallpaper (vinyl chloride), wood (Japanese cedar: untreated), polyvinyl chloride (PVC), low density polyethylene (LDPE), acrylic resin (PMMA), and nylon 6.6 .

The test was carried out on wallpaper and wood formed into small $10 \mathrm{~mm}$ square pieces and PVC, LDPE, PMMA and nylon 6,6 shaped into approximately $3 \mathrm{~mm}$ particles.

\subsection{Test Method}

We performed the combustion tests using tube furnace test equipment as stipulated in ISO 19700, and carried out gas component analysis by FTIR. Figure 3 shows an outline of the test equipment. The tube furnace test involved heating the test bodies at uniform temperatures by sending in air while moving the test body board, and changing the air flow and heating temperature. The test body board was $800 \mathrm{~mm}$ long and the heating furnace $600 \mathrm{~mm}$ long. We sent in primary air while applying heat, then sent secondary air into a mixing and measuring chamber to dilute the generated combustion products before sampling and conducting gas component analysis.

In accordance with ISO 19700, we performed tests under conditions equivalent to five progressive stages of a fire, as shown in Table 2. At stage 1b, we made the weight of all types of test bodies $19.8 \mathrm{~g}(800 \times 25 \mathrm{~g} / \mathrm{mm})$ and the combustion speed $40 \mathrm{~mm} / \mathrm{min}$. Tables 3 and 4 show the weights of test bodies, combustion speeds etc. at stages 2 and 3 , respectively. We conducted all tests for 30 minutes after the start of test heating.

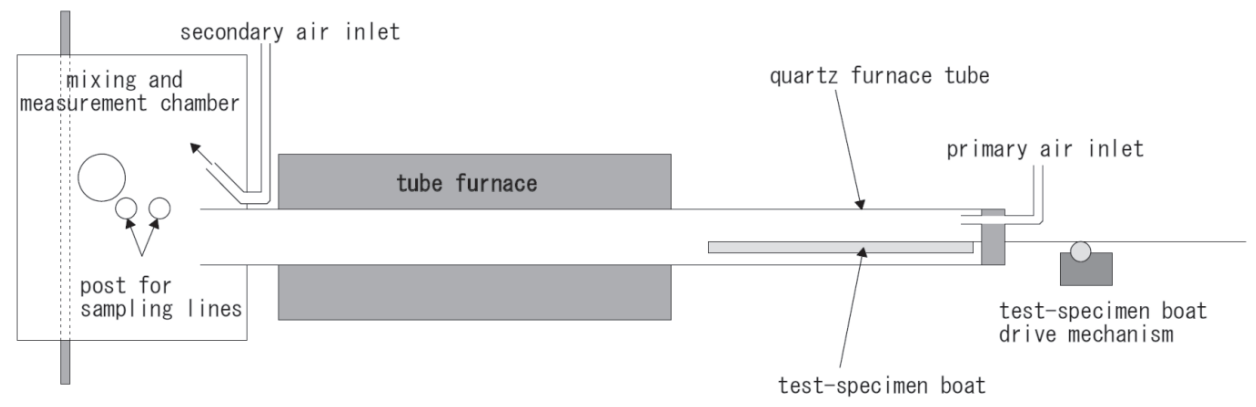

Figure 3 The apparatus of the tube furnace 
Table 2 The test conditions

\begin{tabular}{|c|c|c|c|c|c|}
\hline \multicolumn{3}{|r|}{ Fire stages } & Trun & $\begin{array}{l}\text { primary air } \\
\text { flow }\end{array}$ & $\begin{array}{l}\text { secondary air } \\
\text { flow }\end{array}$ \\
\hline \multicolumn{2}{|c|}{ stage $1 b$} & $\begin{array}{l}\text { oxidative pyrolysis from } \\
\text { externally applied radiation }\end{array}$ & $350^{\circ} \mathrm{C}$ & $2 \mathrm{~L} / \mathrm{min}$ & $8 \mathrm{~L} / \mathrm{min}$ \\
\hline \multicolumn{2}{|c|}{ stage2 } & well-ventilated flaming & $650^{\circ} \mathrm{C}$ & $10 \mathrm{~L} / \mathrm{min}$ & \multirow{3}{*}{$\begin{array}{l}\text { Add up the } \\
\text { primary air } \\
\text { flow to } 50 \mathrm{~L} / \\
\text { min }\end{array}$} \\
\hline \multirow{2}{*}{ stage3 } & stage $3 a$ & $\begin{array}{l}\text { small vitiated fires in closed } \\
\text { or poorly ventilated }\end{array}$ & $650^{\circ} \mathrm{C}$ & $*$ & \\
\hline & stage $3 b$ & $\begin{array}{l}\text { post-flashover fires in open } \\
\text { compartments }\end{array}$ & $825^{\circ} \mathrm{C}$ & * & \\
\hline
\end{tabular}

*using values calculated from the primary air flow rate of stage 2

Table 3 The test conditions of stage 2

\begin{tabular}{|c|c|c|c|c|c|}
\hline & Loading & $\begin{array}{c}\text { Speed of the } \\
\text { boat }\end{array}$ & $\begin{array}{c}\text { Primary air } \\
\text { flow }\end{array}$ & $\begin{array}{c}\text { Secondary } \\
\text { air flow }\end{array}$ & $\begin{array}{l}\text { Furnance } \\
\text { tempreture }\end{array}$ \\
\hline & $\mathrm{g}$ & $\mathrm{mm} / \mathrm{min}$ & $\mathrm{L} / \mathrm{min}$ & $\mathrm{L} / \mathrm{min}$ & ${ }^{\circ} \mathrm{C}$ \\
\hline Wall paper & 39.6 & 60 & \multirow{6}{*}{10} & \multirow{6}{*}{40} & \multirow{6}{*}{650} \\
\hline Wood & 39.6 & 60 & & & \\
\hline PVC & 39.6 & 40 & & & \\
\hline LDPE & 19.8 & 40 & & & \\
\hline PMMA & 22.6 & 40 & & & \\
\hline nylon6,6 & 19.8 & 40 & & & \\
\hline
\end{tabular}

Table 4 The test conditions of stage 3

\begin{tabular}{|c|c|c|c|c|c|c|}
\hline & Loading & $\begin{array}{l}\text { Speed of } \\
\text { the boat }\end{array}$ & $\begin{array}{l}\text { Primary } \\
\text { air flow }\end{array}$ & $\begin{array}{l}\text { Secondary } \\
\text { air flow }\end{array}$ & \multicolumn{2}{|c|}{$\begin{array}{l}\text { Furnance } \\
\text { tempreture }\end{array}$} \\
\hline & $\mathrm{g}$ & $\mathrm{mm} / \mathrm{min}$ & $\mathrm{L} / \mathrm{min}$ & $\mathrm{L} / \mathrm{min}$ & $3 a$ & $3 b$ \\
\hline Wall paper & 39.6 & 60 & 3.2 & 46.8 & \multirow{6}{*}{$650^{\circ} \mathrm{C}$} & \multirow{6}{*}{$825^{\circ} \mathrm{C}$} \\
\hline Wood & 39.6 & 60 & 3.2 & 46.8 & & \\
\hline PVC & 39.6 & 40 & 3.2 & 46.8 & & \\
\hline LDPE & 19.8 & 40 & 3.6 & 46.4 & & \\
\hline PMMA & 22.6 & 40 & 3.4 & 46.6 & & \\
\hline nylon6,6 & 19.8 & 40 & 3.2 & 46.8 & & \\
\hline
\end{tabular}

\subsection{Test Results}

Figure 4 shows the gas concentration measurement results of 4 stages from wood. We substituted the gas composition analysis results obtained from the tests into the ISO 13344 Purser equation and the ISO 13571 harmful gas model (Equations 1 to 3), the calculation results of which are shown in Table 4. A comparison of the figures at each progressive stage of a fire showed that the toxicity and harmfulness of all the test bodies 
except nylon 6,6 was highest at stage 1b. Possible reasons for this are the small amount of secondary air and an environment that facilitated the production of harmful gases due to incomplete combustion. Furthermore, temperature and toxicity show no proportional relationship and tend to vary depending on the material.

Table 5 The calculation results

\begin{tabular}{|l|r|r|r|r|r|r|r|r|r|r|r|r|}
\hline & \multicolumn{3}{|c|}{ stage1b } & \multicolumn{3}{c|}{ stage2 } & \multicolumn{3}{c|}{ stage3a } & \multicolumn{3}{c|}{ stage3b } \\
\cline { 2 - 14 } & IS013344 & \multicolumn{2}{|c|}{ IS013571 } & IS013344 & \multicolumn{1}{|c|}{ IS013571 } & IS013344 & IS013571 & IS013344 & \multicolumn{2}{|c|}{ IS013571 } \\
\cline { 2 - 13 } & $\begin{array}{c}\mathrm{L}_{\mathrm{FED}} \\
\text { (Purser }\end{array}$ & $\mathrm{X}_{\mathrm{FED}}$ & $\mathrm{X}_{\mathrm{FEC}}$ & $\begin{array}{c}\mathrm{L}_{\mathrm{FED}} \\
\text { (Purser }\end{array}$ & $\mathrm{X}_{\mathrm{FED}}$ & $\mathrm{X}_{\mathrm{FEC}}$ & $\begin{array}{c}\mathrm{L}_{\mathrm{FED}} \\
\text { (Purser }\end{array}$ & $\mathrm{X}_{\mathrm{FED}}$ & $\mathrm{X}_{\mathrm{FEC}}$ & $\begin{array}{c}\mathrm{L}_{\mathrm{FED}} \\
\text { (Purser }\end{array}$ & $\mathrm{X}_{\mathrm{FED}}$ & $\mathrm{X}_{\mathrm{FEC}}$ \\
\hline wall paper & 3.78 & 1.63 & 8.28 & 1.62 & 0.43 & 0.47 & 1.86 & 0.57 & 1.37 & 1.59 & 0.42 & 0.41 \\
\hline wood & 7.59 & 14.03 & 8.65 & 1.53 & 0.47 & 0.12 & 2.25 & 1.86 & 1.97 & 3.13 & 6.12 & 2.18 \\
\hline PVC & 6.38 & 0.71 & 20.31 & 2.56 & 1.11 & 3.59 & 1.78 & 0.27 & 1.16 & 1.35 & 0.01 & 0.01 \\
\hline LDPE & 12.60 & 5.49 & 27.87 & 2.42 & 4.77 & 1.40 & 1.36 & 0.00 & 0.02 & 2.23 & 2.01 & 1.77 \\
\hline PMMA & 265940 & 1.50 & 2419595 & 1.44 & 0.13 & 0.08 & 5.30 & 8.84 & 9.09 & 1.60 & 0.62 & 0.30 \\
\hline nylon6,6 & 1.57 & 0.02 & 0.61 & 1.64 & 0.72 & 0.23 & 1.36 & 0.01 & 0.02 & 3.91 & 92.20 & 2.58 \\
\hline
\end{tabular}

\subsection{Considerations}

We realized that the relationship between toxicity and temperature of the gases produced in a fire varied depending on the material. Furthermore, we evaluated the lethal toxicity, irritant effect and suffocating effect of each material and were able to confirm that, in different fire spaces, the same material had a varying impact on escape at each progressive stage of the fire, and to clarify the materials' characteristics and how to investigate them.

In comparison with every fire stages, the effect of both suffocating and irritant of all specimens(except nylon6,6) are highest in stage1. It can be said that the influence of gas to evacuee is most serious in the incipient stage of a fire.

\section{IMPACT ON EVACUATION SAFETY OF COMBUSTION PRODUCT GASES}

Whether or not the allowable escape time exceeds the required escape time can be used as a criterion for assessing safety to human life. The suffocating effect of a hazardous gas does serious harm to the human body culminating in death or behavioral arrest, but can be judged to be safe if the allowable escape time is longer than the required escape time. The irritant effect delays the escape action, speed of movement, choice of escape route, etc. of people inside a building, which lengthens the required escape time perhaps even beyond the allowable escape time, thereby increasing the risk of being unable to escape to safety. In this way, the suffocating effect and irritant effect work differently to the human body. Therefore, we need to consider both effect of hazardous gases when evaluating the toxicity of gases produced during a fire. Below we propose a way of doing this[5]. 
Where $t_{\text {escape }}$ is the required escape time, $t_{\text {limit }}$ the allowable escape time, $t_{\text {stop }}$ the behavioral arrest time, and $\alpha$ the coefficient from the evaluation of the irritant effect $\mathrm{X}_{\mathrm{FEC}}$, the situation is safe if formula below is satisfied.

$$
\begin{aligned}
& t_{\text {limit }}>\alpha t_{\text {escape }} \\
& t_{\text {stop }}>\alpha t_{\text {escape }} .
\end{aligned}
$$



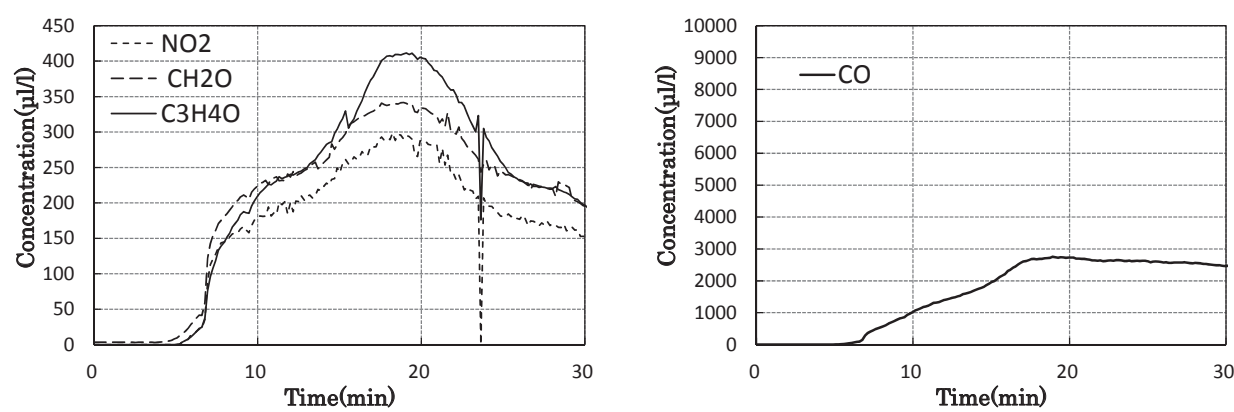

(a)stage $1 b$
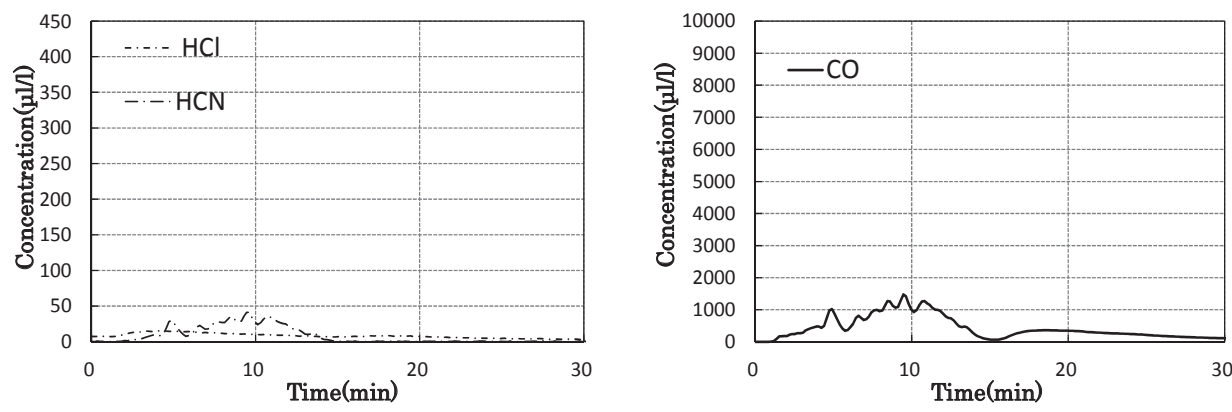

(b) stage 2
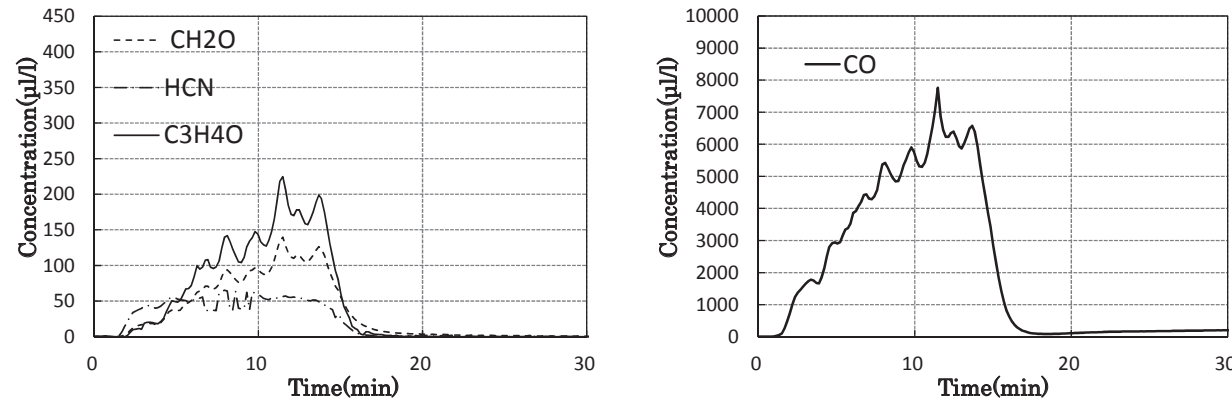

(c) stage $3 \mathrm{a}$
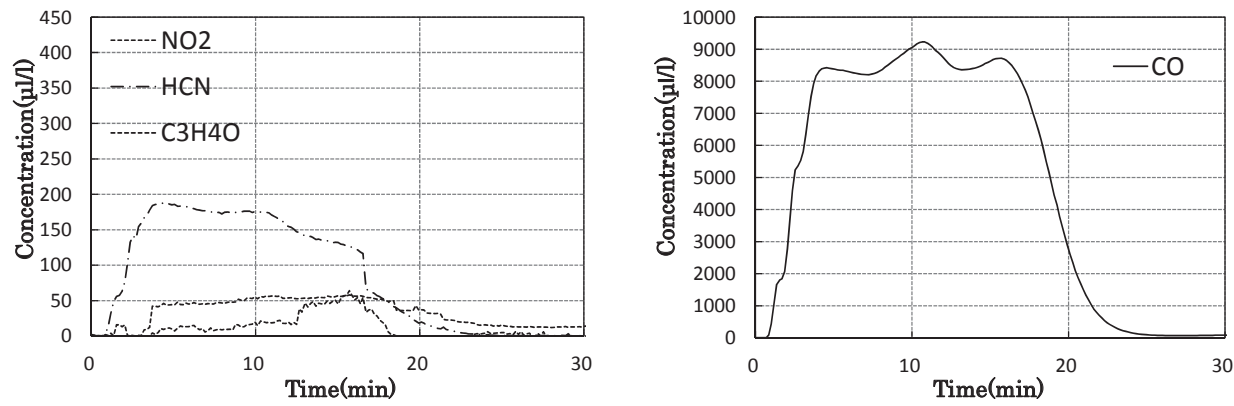

(d) stage $3 b$

Figure 4 The gas concentration measurement results of 4 stages from wood 
With (1), we need to calculate the required escape time $t_{\text {escape }}$ of human beings exposed to a hazardous gas in an actual building. With (2), we need to calculate a for the irritant effect of the gas in the actual building, but first we have to evaluate the gas hazard effect (including both suffocation and irritation) for each building material in the heating test.

Because the time when the sum of $\mathrm{X}_{\mathrm{FEC}}$ or $\mathrm{X}_{\mathrm{FED}}$ exceeds a set threshold represents the allowable escape time in those safety standards[2], $t_{\text {limit }}$ can be calculated from FEC or FED. In the same way, $t_{\text {stop }}$ can be calculated from the lethal toxicity $\mathrm{L}_{\mathrm{FED}}$.

The required escape time $t_{\text {escape }}$ is the sum of the escape action time and the escape start time, and can be found using the following equation[3].

(a) In room where fire breaks out

$$
\begin{aligned}
& t_{\text {start }, \text { room }}=2 \sqrt{A} \\
& t_{\text {move }, \text { room }}=\frac{l_{\text {max }, \text { room }}}{v}+\frac{P_{\text {room }}}{N B} \\
& t_{\text {escape }}=t_{\text {start }, \text { room }}+t_{\text {move }, \text { room }}
\end{aligned}
$$

$\mathrm{t}_{\text {start,room }}$ : Escape start time in room where fire breaks out $(\mathrm{s})$

$\mathrm{t}_{\text {moveroom }}$ : Movement escape time in room where fire breaks out $(\mathrm{s})$

$1_{\text {max }, \text { room }}$ : Maximum walking distance $(\mathrm{m})$

$\mathrm{A}$ : Floor area $\left(\mathrm{m}^{2}\right)$

$\mathrm{v}$ : Walking speed $(\mathrm{m} / \mathrm{s})$

$\mathrm{P}_{\text {room }}:$ No. of people in room

$\mathrm{N}:$ Flow coefficient (people/m·s)

$\mathrm{B}:$ Width of exit $(\mathrm{m})$

(b) On floor where fire breaks out

$$
\begin{aligned}
& t_{\text {start,floor }}=2 \sqrt{A_{\text {floor }}}+a \\
& t_{\text {move, floor }}=\frac{l_{\text {max }, \text { floor }}}{v}+\frac{P_{\text {floor }}}{N B_{\min }} \\
& t_{\text {escape }}=t_{\text {start }, \text { floor }}+t_{\text {move, floor }}
\end{aligned}
$$

$t_{\text {start,room }}$ : Escape start time on floor where fire breaks out $(\mathrm{s})$

$t_{\text {moveroom }}$ : Movement escape time on floor where fire breaks out $(\mathrm{s})$

$l_{\text {max,room }}$ : Distance from area on each floor where people must escape to assumed escape point on floor where fire breaks out $(\mathrm{m})$

A : Total floor area of all rooms $\left(\mathrm{m}^{2}\right)$

$\mathrm{v}$ : Walking speed $(\mathrm{m} / \mathrm{s})$

$\mathrm{P}_{\text {floor }}$ : No. of people who must use exit to assumed escape point on floor where fire breaks out $\mathrm{N}$ : Flow coefficient (people/m·s)

$\mathrm{B}_{\min }$ : Width of narrowest door on escape route (m) 
$\alpha$ is the coefficient from the evaluation of the irritant effect FEC, considering the reduction in walking speed having received the irritant effect of a gas, and is obtained from the relationship between the density or type of irritant smoke and the walking speed of the escapee. In Equations 4.4 .1 and 4.4.2, $v_{\mathrm{FEC}}$ is substituted by $\alpha v$ to find the required escape time taking into account the irritant effect. For $\alpha$, we propose the following calculation method.

The graph below[4] shows walking speed and smoke density in irritant smoke and non-irritant smoke.

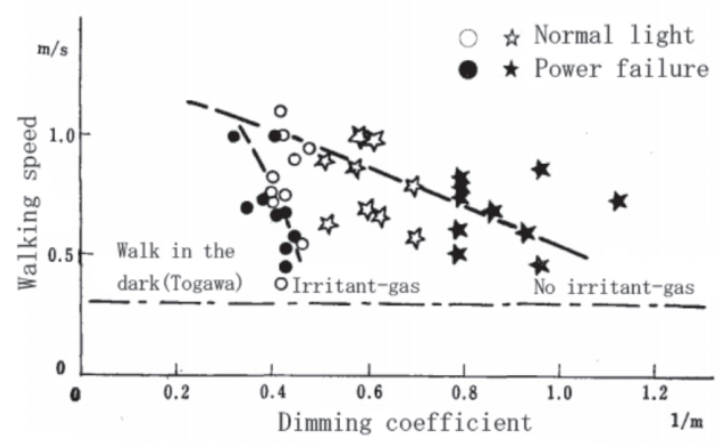

We produced irritant smoke by burning a wooden crib with extremely narrow gaps, and non-irritant smoke with a relatively low level of irritation by burning kerosene.

The approximate linear function of the relationships between irritant and nonirritant smoke and the light reduction coefficient are taken as $\mathrm{y}_{1}$ and $\mathrm{y}_{2}$ respectively. If we take two points along $\mathrm{y}_{1}(\mathrm{x}, \mathrm{y})=(0.45,0.5),(0.35,1.0)$ and two points along $\mathrm{y}_{2}(\mathrm{x}, \mathrm{y})=$ $(1.05,0.5)$ and $(0.45,1), \mathrm{y}_{1}$ and $\mathrm{y}_{2}$ are as follows.

$$
y_{1}=-5 x+\frac{11}{4} \quad, \quad y_{2}=-\frac{5}{6} x+\frac{11}{8}
$$

Comparing the walking speed in smoke with the same light reduction coefficient, and using

$$
\begin{aligned}
& \alpha=\frac{y_{2}}{y_{1}} \\
& \alpha=\frac{33-20 x}{55-120 x}
\end{aligned}
$$

Assuming the effect of irritant smoke on walking speed airr is proportional to the effective concentration FEC, the value of the effective concentration FEC of wood in stage 2 of our tube furnace test is 0.47 , so we can find $\alpha_{i r}$ as follows.

$$
\begin{aligned}
& \alpha \leq 1, \quad \alpha_{\text {irr }}=\frac{X_{F E C, \text { irr }}}{0.47} \frac{33-20 x}{55-120 x} \\
& \alpha \geq 1, \quad \alpha_{\text {irr }}=1
\end{aligned}
$$




\section{SUMMARY AND FUTURE CHALLENGES}

From this research, we obtained the following results.

It is carried out heating tests on building materials using gas toxicity test equipment and confirmed that it was possible to quantify the impact of combustion gases on the human body through gas component analysis by FTIR.

It is carried out heating tests on building materials using a tube furnace and found that the relationship between the toxicity of gases produced in a fire and the temperature varied depending on the type of material. We also confirmed that the same material had a varying impact on escape at each progressive stage of the fire, and that trends shown in toxicity values of combustion product gases can be attributed to heating conditions.

It is proposed an evacuation safety evaluation method that takes into account the effect of hazardous gases, making it possible to evaluate the impact of combustion products on evacuation safety during a fire from the lethal toxicity, suffocating effect, and irritant effect of their hazardous gases.

Going forward, It is planned to check the validity of our proposed evaluation method and, based on the results of assessing the combustion properties of building materials during fires, to formulate a method of evaluating the impact of hazardous gases on evacuation safety in actual building spaces.

\section{ACKNOWLEDGEMENT}

Authors would like to express deepest gratitude to Mr. Tatsuo Ando who offered generous support.

\section{REFERENCES}

1. ISO 13571-2012 Life-threatening components of fire -Guidelines for the estimation of time to compromised tenability in fires ISO 13344-2004 Estimation of the lethal toxic potency of fire effluents

2. ISO 13344-2004 Estimation of the lethal toxic potency of fire effluents

3. Building Center of Japan: New disaster prevention plan guidance, manual of building fire prevention and evacuation planning, 1995 (in Japanese)

4. Tadahisa JIN : About the walking speed in the smoke, KASAI, Vol.25 No.2, 1975 (in Japanese)

5. Xuansu Zhao, Takafumi Noguchi,Tomohiro Naruse, Hideki Yoshioka, Yutaka Tanaike, Satoshi Fujimoto, Yoshihiro Hase, Tetsuya Hayakawa, Tatuso Ando, The influence of gas produced on refuge safety at the time of fire -One consideration of the fire smoke gas in the Smoke Toxicity Test based on FTIR analysis-, 10th AOSFST, 2015 